\title{
Invasive intestinal mucormycosis in a 40- year old immunocompetent patient - a rarely reported clinical phenomenon: a case report
}

Abdi Bati Wotiye ${ }^{1,2^{*}}$, Poornachandra $\mathrm{KS}^{1}$ and Biniyam Alemayehu Ayele ${ }^{3}$

\begin{abstract}
Background: Mucormycosis is rare, life-threatening fungal infection. Frequently observed in those patients having underlying immunosuppression such as, diabetes, organ transplantation, Human immunodeficiency virus (HIV) infection, and elevated serum iron. However, invasive intestinal mucormycosis occurring in immunocompetent individuals without the traditional risk factors is extremely rare clinical phenomenon.

Case presentation: We report a 40-year-old male patient who presented with 1 week history of diffuse abdominal pain and high grade fever, associated with vomiting and frequent loose stools. Has history of chronic alcohol ingestion. Otherwise, no past history of chronic medical illness, nor he had contact with individuals with similar illness. He was in a septic shock with multiple organ failure up on presentation to emergency room. Physical examination revealed icterus sclera with abdominal tenderness. He was immediately resuscitated using crystalloids, supported with inotrope, and antibiotics. Histopathological examination of tissue sample from colonic ulcer biopsy revealed invasive intestinal mucormycosis. Patient showed full clinical and histopathological resolution after course of parenteral Liposomal Amphotercin B.

Conclusion: This case highlights the fact that, despite its life-threatening nature, it's possible to treat patients with invasive intestinal mucormycosis with aggressive antifungal and supportive care without surgical intervention, provided that all the necessary supportive care were initiated early and the disease was diagnosed early and appropriate medical management was initiated timely. In addition, it's important to consider intestinal mucormycosis even in patients who are immunocompetent without traditional risk factors.
\end{abstract}

Keywords: Mucormycosis, Intestinal invasive, Immunocompetent

\footnotetext{
* Correspondence: batiabdi@gmail.com; dr.abdi@hu.edu.et

'Department of Gastroenterology and Hepatology, Fortis Hospital, Bannerghata Road, Bangalore, India

${ }^{2}$ Department of Internal Medicine, College of Medicine and Health Sciences, Hawassa University, Hawassa, Ethiopia

Full list of author information is available at the end of the article
}

C C The Author(s). 2020 Open Access This article is licensed under a Creative Commons Attribution 4.0 International License, which permits use, sharing, adaptation, distribution and reproduction in any medium or format, as long as you give appropriate credit to the original author(s) and the source, provide a link to the Creative Commons licence, and indicate if changes were made. The images or other third party material in this article are included in the article's Creative Commons. licence, unless indicated otherwise in a credit line to the material. If material is not included in the article's Creative Commons licence and your intended use is not permitted by statutory regulation or exceeds the permitted use, you will need to obtain permission directly from the copyright holder. To view a copy of this licence, visit http://creativecommons.org/licenses/by/4.0/ The Creative Commons Public Domain Dedication waiver (http://creativecommons.org/publicdomain/zero/1.0/) applies to the data made available in this article, unless otherwise stated in a credit line to the data. 


\section{Background}

Mucormycosis is an uncommon, life-threatening infection caused by fungi belonging to the subphylum Mucormycotina, order Mucorales. Among organisms responsible for causing mucormycosis, Rhizopus species are the most common cause of infection. The major portals of entry include the sinuses, lungs, gastrointestinal tract and skin [1, 2]. Mucormycosis mostly affects immunocompromised hosts including patients with diabetes, malignancy, HIV, organ transplant recipients and patients on immunosuppressive therapy [3]. While any organ system may be affected, rhino-orbital-cerebral and pulmonary infections dominate the literature [3-5]. Very few cases of gastrointestinal mucormycosis in an immunocompetent host have been reported $[5,6]$. The aim of this case report is to highlight the importance of early detection and aggressive medical management of invasive mucormycosis may result in good outcome.

\section{Case presentation}

This is a 40-year old man referred from local health facility to our hospital with diagnosis of acalculous cholecystitis after he presented with a week history of diffuse abdominal pain and high grade fever. Associated with this he had history of vomiting and frequent loose stools. He had history of chronic alcohol abuse. He has no urinary complaints, no past history of hypertension, diabetes mellitus, dyslipidemia or cardiac illness. No history of similar illness in the family and in his neighborhood. No history of contact with individuals suffering from similar illness, or traveling to region where such illness is common. He runs small business in the town. Physical examination showed emaciated but fully conscious. Vital signs were, Blood pressure $=80 / 50 \mathrm{mmHg}$, Pulse rate $=115 /$ beat $/ \mathrm{mi}$ nute, Temp $=99.6^{\circ} \mathrm{F}$, and $R R=26$ breath $/$ minute. Venous blood gas (VBG) analysis was suggestive of metabolic acidosis. He had scleral icterus bilaterally. In addition he had superficial and deep abdominal tenderness in epigastric and right upper quadrant region.
Abdominal ultrasound showed mild hepatomegaly with mild course increased echo pattern, gall bladder wall thickening with mild pericholecystic fluid collection and mild ascites. Otherwise, the patient had no overt signs of liver cirrhosis. Computed tomography (CT) showed Gall bladder wall edema with intense pericholecystic fat stranding and free fluid around liver and spleen (Fig. 1a, b). There was mild ascites, nodular liver contours. The colon showed edematous thickening and ulcer at right transverse colon and hepatic flexure (Fig. 2a, b).

He was admitted to medical ICU and started on parenteral antibiotics and inotropes and resuscitated with intravenous fluids. Urine and blood culture were negative. $\mathrm{He}$ was negative for Dengue IgM. On second day our patient's condition was deteriorating despite broad spectrum antibiotics with persisting Fever, acidosis, patient become delirious, and lactate remained high (Table 1). Abdominal examinations showed increased tympanicity and diffuse tenderness. The patient was evaluated by GI surgeon and taken up for diagnostic laparotomy. Subsequently, mini laparotomy and cholecystotomy was done due to severe adhesions. Gall bladder fluid analysis was unremarkable, culture was negative, but histopathologic examination was not done as cholecystectomy was performed. On day 4, colonoscopy was done and sample was sent for histopathological analysis. Histopathology report revealed an acute suppurative inflammation of the colon mucosa with extensive areas of necrosis (Fig. 3a, b) and the detection of many wide, ribbon-like, sparsely septated fungal hyphae with wide-angle branching (approximately $90^{\circ}$ ), characteristic of zygomycetes species and thus consistent with mucormycosis (Fig. 4a, b). Microbiological culture and species subtyping was not done.

After diagnosis of invasive intestinal mucormycosis was confirmed by colonic biopsy results, antifungal medication with intravenous liposomal amphotericin B at a dose of 5 $\mathrm{mg} / \mathrm{kg}$ daily was started on seventh day of admission. Lipid formulation of amphotericin B, rather than amphotericin B deoxycholate was selected, in order to deliver a high dose with less nephrotoxicity. Subsequently patient

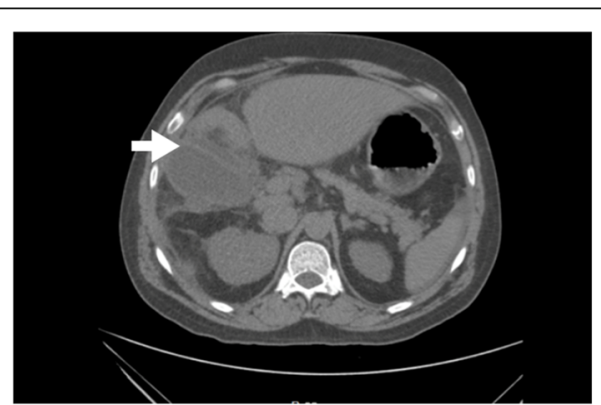

A

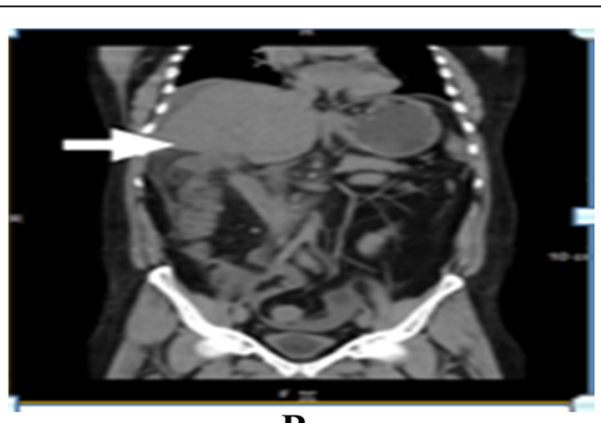

B

Fig. 1 a, b:Axial and coronal CT scan of abdomen showing gall bladder wall edema with intense pericholecystic fat stranding (white arrow), free fluid around liver and showing edematous thickening (white arrow) at hepatic flexure 


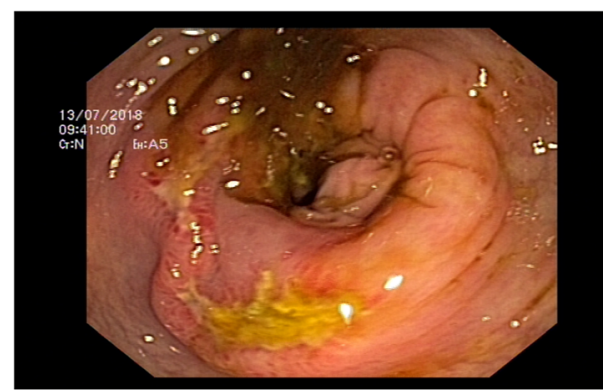

A

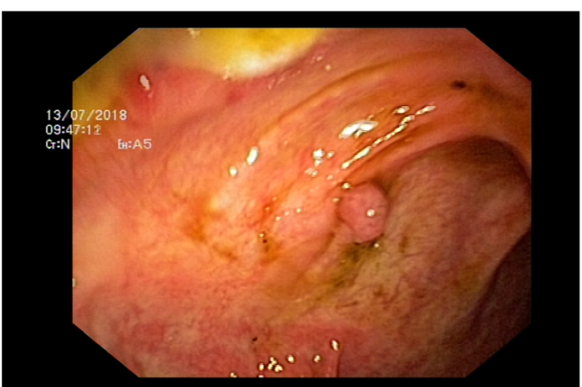

B

Fig. 2 a Right transverse colon and hepatic flexure video colonoscopy image showing transverse ulcer with edematous mucosa. b showing a sessile polyp near the ulcer

become afebrile and showed clinical improvement. Unfortunately, the patient developed acute kidney injury (Table 1) secondary to amphotericin $B$ therapy, for which the drug was withdrawn for 2 days while the patient was kept received supportive care, latter antifungal treatment was resumed after $48 \mathrm{~h}$. After receiving amphotericin B accumulative dose of $1.8 \mathrm{~g}$ patient clinical condition improved significantly. Finally he was discharged to local hospital to complete his total dose of $3.2 \mathrm{~g}$ of amphotericin B.

Even though intestinal mucormycosis carries high mortality even with treatment, our patient clinical manifestation improved significantly following antifungal treatment without surgical resection of necrotic tissue. This may highlight mucormycosis may have good prognosis if occurred in immunocompetent patients. Before his discharge

Table 1 Patient's Laboratory test, results and references

\begin{tabular}{|c|c|c|}
\hline Laboratory tests & Results & Reference range \\
\hline WBC & $\begin{array}{l}11,700 \text { cells } / \mathrm{mm}^{3} \\
\text { (N\% 79) }\end{array}$ & $\begin{array}{l}4500-10,000 \text { cells/ } \\
\mathrm{mm}^{3}\end{array}$ \\
\hline Platelet count & $\begin{array}{l}116,000 \text { cells/ } \\
\mathrm{mm}^{3}\end{array}$ & $\begin{array}{l}150,000 \text { to } 450,000 \\
\text { cells } / \mathrm{mm}^{3}\end{array}$ \\
\hline Hemoglobin & $13.3 \mathrm{~g} / \mathrm{dL}$ & 14.0 to $17.5 \mathrm{~g} / \mathrm{dL}$ \\
\hline Urea & $71 \mathrm{mg} / \mathrm{dL}$ & $4.3-22.4$ \\
\hline Creatinine & $2.29 \mathrm{mg} / \mathrm{dL}$ & $5.1-14$ \\
\hline SGOT & $62 \mathrm{U} / \mathrm{L}$ & 0-35 U/L \\
\hline SGPT & $19 \mathrm{U} / \mathrm{L}$ & 0-35 U/L \\
\hline Total bilirubin & $3.14 \mathrm{mg} / \mathrm{dL}$ & $0.3-1.0 \mathrm{mg} / \mathrm{dL}$ \\
\hline Direct bilirubin & $3.03 \mathrm{mg} / \mathrm{dL}$ & $0.1-0.3 \mathrm{mg} / \mathrm{dL}$ \\
\hline Alkaline phosphatase & $110 \mathrm{U} / \mathrm{L}$ & $30-120 \mathrm{U} / \mathrm{L}$ \\
\hline GGT & $60 \mathrm{U} / \mathrm{L}$ & 9-50 U/L \\
\hline Sodium & $140 \mathrm{mEq} / \mathrm{L}$ & $136-145 \mathrm{mEq} / \mathrm{L}$ \\
\hline Potassium & $3.87 \mathrm{mEq} / \mathrm{L}$ & $3.5-5.0 \mathrm{mEq} / \mathrm{L}$ \\
\hline Lactate & $38 \mathrm{mmol} / \mathrm{L}$ & $0.7-2.1 \mathrm{mmol} / \mathrm{L}$ \\
\hline Fasting blood glucose & $90 \mathrm{mg} / \mathrm{dL}$ & $70-99$ mg/dL \\
\hline $\begin{array}{l}\text { HIV } 1 / 2, \text { HBSAg and anti } \\
\text { HCV }\end{array}$ & & Negative \\
\hline
\end{tabular}

the patient was screened for possible potential underlying predisposing factors such as diabetes mellitus, malignancy and HIV infection (Table 1), but he was negative for all. The only possible predisposing factor we identified was chronic alcoholism with high potential of liver cirrhosis. Patient was re-evaluated 2 weeks after his discharge and completion of his antifungal medication, he remained clinically stable and his liver and renal function tests were in normal range. Follow-up colonoscopy done showed healing hepatic flexure ulcers (Fig. 5a). Colonoscopy was repeated on 6 weeks follow up and showed healed hepatic flexure ulcers (Fig. 5b).

\section{Discussion and conclusion}

Mucormycosis is a life-threatening fungal infection caused by Mucorales, primarily affecting the immunocompromised hosts. Almost all patients with invasive mucormycosis have some underlying disease that both predisposes to the infection and influences the clinical presentation. However, it's uncommon for immunocompetent patient to develop invasive life-threatening mucormycosis. Our case had no traditional risk factors often predisposing the patient to invasive mucormycosis. We only identified chronic alcoholic usage and early signs of liver cirrhosis as underlying risk factor in our patient $[4,7]$. Despite the fact that invasive mucormycosis is lethal in more than half of the patient [1], yet our patient showed excellent clinical responses to anti-fungal treatment alone without surgical resection of necrotic tissue. This benign course observed in our case is indicative of good outcome is possible if managed properly, especially in patient lacking traditional risk factors.

Involvement of gastrointestinal system by mucormycosis is dominated by involvement of the stomach in $67 \%$, whereas the intestine is involved in $25 \%$ of the case. Intestinal mucormycosis has wide range of clinical manifestation, ranging from presenting with peptic ulcer disease to an aggressive and life threatening intestinal invasion by fungal filaments causing systemic fungemia $[5$, 


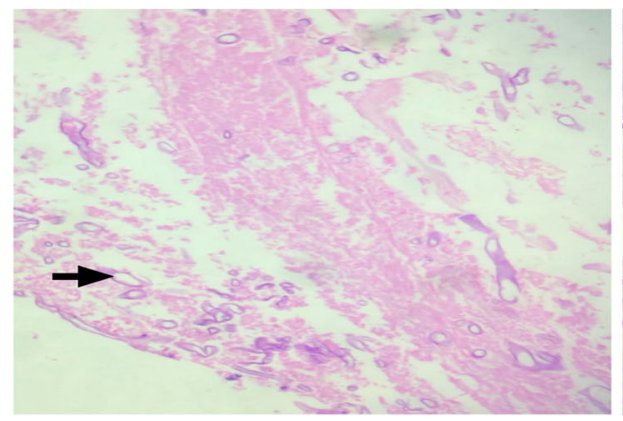

A

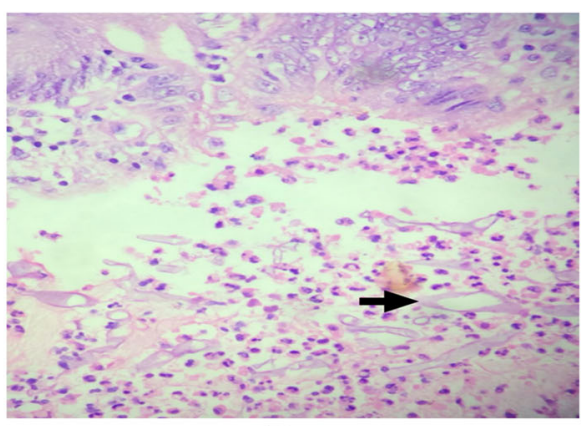

B

Fig. 3 a Colon biopsies (hematoxylin and eosin (H\&E) stain; 100x) from the center of a mucosal ulceration with sparsely septated hyphae of zygomycetes (black arrow) lying in fibrinous exudate. b Biopsy from a colon polyp with surface deposits of fungal filaments of zygomycetes (black arrow) lying in an acute suppurative inflammation exudate

6, 8]. The pathologic hallmark of mucormycosis is infarction of host tissue resulting from angioinvasion by fungal hyphae. This gives rise to necrotic ulcers with resultant acute abdominal pain, hematemesis, perforation and peritonitis. The patient is often thought to have an intraabdominal abscess $[1,2]$. Ante-mortem diagnosis of mucormycosis is made in only 25 to $50 \%$ of cases, as its extremely rare disease with significant fatal outcome even with treatment. Cultures are usually negative and no reliable serologic tests are currently available. The diagnosis is nearly always made by biopsy of the suspected area during or after surgery or endoscopy, or at autopsy $[1,2,5,9,10]$.

Treatment of mucormycosis involves a combination of antifungal therapy with surgical debridement of infected and necrotic tissues $[4-6,10]$. Additionally, early identification and treatment of an underlying predisposing factors, such as diabetes mellitus, immunosuppressive drugs, and neutropenia, chronic alcoholism, and HIV infection is vital to successfully treat invasive mucormycosis $[5,8,11]$.

Gastro-intestinal mucormycosis has mortality rate of approximately $50 \%[1,5,10,11]$. Contrary to this fact, our patient has no identifiable traditional risk factors (Table 1), except history of chronic alcohol use. Furthermore, the patient was successfully treated without surgical resection with liposomal Amphotercin B further supporting the uniqueness of the case. Our patient received a total dose of 3.2grmas of Ampotercine B throughout the treatment course, in line with the recommended treatment regimen for such patients. Subsequently eradication of fungal infection was supported by normal follow up histopathological findings and normal follow-up colonoscopy examination.

Invasive intestinal mucormycosis is one of the rarest life-threatening fungal infection, because of this its vita to identify the illness early and initiate antifungal medication. Despite its high mortality our patient was salvaged because of the following critical measures: the patient was immediately admitted to medical ICU and resuscitation was initiated immediately using crystalloid fluid and inotropes. On top of this he was started on broad spectrum antibiotics in order to cover septicemia of pyogenic origin. In addition, the patient was re-evaluated frequently in order to detect any life threating complications, because of this he had abdominal CT and colonoscopy within few days of his admission and latter cholecystotomy was done to drain gall bladder collection. Finally histopathological results were made available in short period of time, which lead to initiation of antifungal drug.

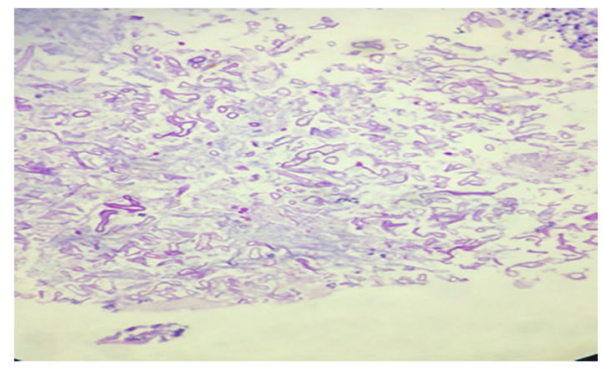

A

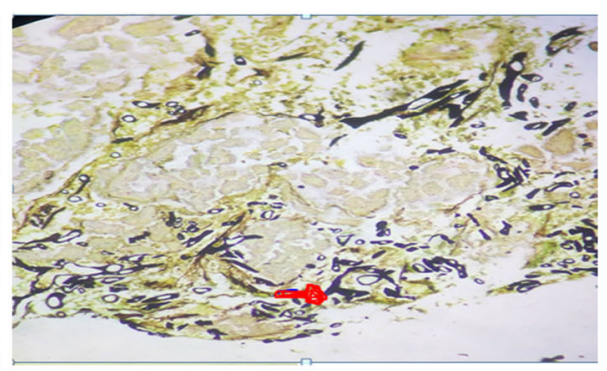

B

Fig. 4 a \& b Periodic acid-Schiff (PAS) stain and (B) Gomori Methenamine-Silver stain (GMS) highlighting the wide, ribbon-like, sparsely septated hyphae with wide-angle branching (approximately $90^{\circ}$; arrow), characteristic of zygomycetes species 


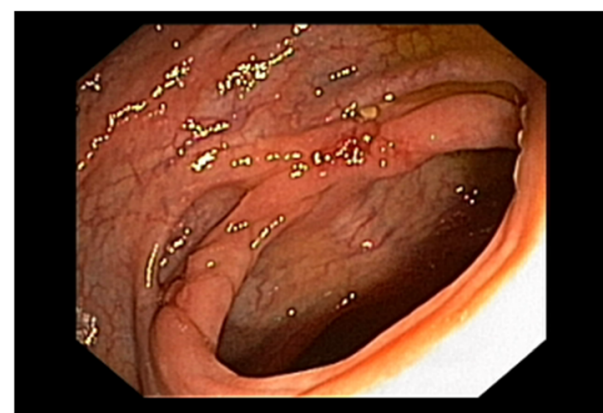

A

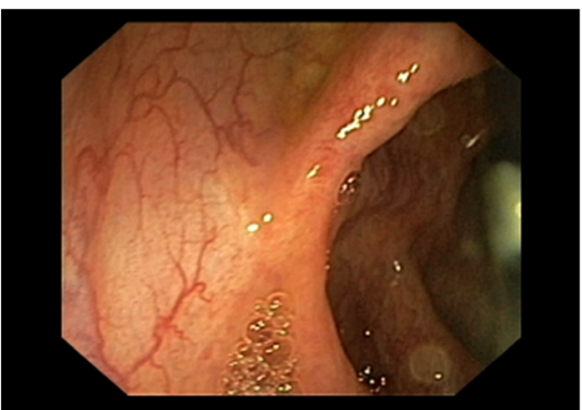

B

Fig. 5 a, b Follow-up colonoscopy (At 2 weeks) showing healing ulcers in right transverse colon and hepatic flexure of the colon (a) and Followup colonoscopy at 6 weeks showing healed ulcer with scaring (b)

Limitations to our approaches and management of this patient were: inability to remove the infected intestinal segment, lack of histopathological examination and biopsy gall bladder, even though patient was treated with antifungal, delayed diagnosis of mucormycosis is a serious and often fatal fungal infection and diagnosis is fraught with challenges due to its non-specific clinical features and need of invasive interventions. However, we report a case of immunocompetent patient with invasive intestinal mucormycosis being managed solely by parenteral antifungal medication without surgical resection and yet fully recovered from his illness after full course of antifungal treatment. Therefore, a high degree of clinical suspicion and early diagnosis helps in prompt antifungal therapy and improvement in survival.

\section{Abbreviations}

AKI: Acute kidney injury; AMB: Amphotercin; BP: Blood pressure; CT: Computed tomography; ER: Emergency room; GGT: Gammaglutamyltransferase; GMS: Gomori methenamine-silver; HCV: Hepatitis C virus; HIV: Human immunodeficiency virus; IV: Intravenous; LAMB: Liposomal Amphotercine B; ${ }^{\circ}$ F: Degree fahrenheit; PAS: Periodic acid shift; SGOT: Aspartate aminotransferase; SGPT: Alanine aminotransferase; VBG: Venous blood gas

\section{Acknowledgements}

We would like to acknowledge our patient for his support.

\section{Authors' contributions}

$A B$ and PKS participated in evaluation, investigation, management, and follow up of the patient, while BA involved in case analysis, manuscript preparation and manuscript editing. Finally, all authors have read and approved the manuscript before submission.

\section{Funding}

No funding was received from any organization or individuals.

\section{Availability of data and materials}

All data sets on which the conclusions of the case report based, to be available as spread sheets documents and available from the corresponding author on reasonable request from the editor.
Ethics approval and consent to participate

Authors' institution does not require ethical approval for publication of a single case report.

\section{Consent for publication}

The patient had provided written informed consent to the publication of his personal information, clinical details, and de-identified CT scans, histological and colonoscopy images. Copy of the consent will be available from the corresponding author on reasonable request from the editor.

\section{Competing interests}

The authors declare that they have no competing interests.

\section{Author details}

'Department of Gastroenterology and Hepatology, Fortis Hospital, Bannerghata Road, Bangalore, India. ${ }^{2}$ Department of Internal Medicine, College of Medicine and Health Sciences, Hawassa University, Hawassa, Ethiopia. ${ }^{3}$ Department of Neurology, College of Health Sciences, Addis Ababa University, PoBox 6396, Addis Ababa, Ethiopia.

Received: 19 September 2019 Accepted: 21 February 2020 Published online: 06 March 2020

\section{References}

1. Ribes JA, Vanover-Sams CL, Baker DJ. Zygomycetes in human disease. Clin Microbiol Rev. 2000;13:236-301.

2. Spellberg B, Edwards JIA. Novel perspectives on Mucormycosis: pathopsyology, presentation, and management. Clin Microbiol Rev. 2005;18: 556-69.

3. Maertens JH, Demuynck EK, Zache'e VP, Vandenberghe GEVP, Boogaerts MA. Mucormycosis in allogeneic bone marrow transplant recipients: report of five cases and review of the role of iron overload in the pathogenesis. Bone Marrow Transplant. 1999:24:307-12.

4. Marianne M, Adam N, Leon B, David S. "We are what we eat!" . Invasive intestinal mucormycosis: A case report and review of the littérature. Med Mycol Case Rep. 2012:52-5. https://doi.org/10.1016/j.mmcr.2012.07.003.

5. Roden M, Zaoutis T. Epidemiology and outcome of zygomycosis: a review of 929 reported cases. Clin Infect Dis. 2005;41(5):634-53.

6. Bruno F, Barros B, Márcio LD, Lucas RS, Angelo S, Felipe NF. A rare case of gastric mucormycosis in an immunocompetent patient. Rev Soc Bras Med Trop. 2018;51(3):401-2. https://doi.org/10.1590/0037-8682-0304-2017.

7. Ho YH, Wu BG, Chen YZ, Wang LS. Gastric mucormycosis in an alcoholic with review of the literature. Tzu Chi Med J. 2007;19:169-72.

8. Barnajian M, Gioia W, lordache F, Bergamaschi R. Mucormycosis-induced Colon perforation after renal transplantation. Surg Infect. 2014. https://doi. org/10.1089/sur.2013.131

9. Petrikkos G, Skiada A, Lortholary O, Roilides E, Walsh TJ, Kontoyiannis DP. Epidemiology and clinical manifestations of Mucormycosis. Clin Infect Dis. 2012;54:23-34. 
10. Hariprasath $P$, Anup KG, Shivaprakash MR, Pankaj S, Immaculata X, Jayanthi S, Umabala P, Joseph J, Subhash V, Ashim D, Naresh KP, Surjit S, Amanjit B, Arunaloke C. A prospective multicenter study on mucormycosis in India: Epidemiology, diagnosis, and treatment. Med Mycol, myy060. https://doi. org/10.1093/mmy/myy06.

11. Jeong $\mathbf{W}$. The epidemiology and clinical manifestations of mucormycosis: a systematic review and meta- analysis of case reports. Clin Microbiol Infect. 2018. https://doi.org/10.1016/j.cmi.2018.07.011.

\section{Publisher's Note}

Springer Nature remains neutral with regard to jurisdictional claims in published maps and institutional affiliations.

Ready to submit your research? Choose BMC and benefit from:

- fast, convenient online submission

- thorough peer review by experienced researchers in your field

- rapid publication on acceptance

- support for research data, including large and complex data types

- gold Open Access which fosters wider collaboration and increased citations

- maximum visibility for your research: over $100 \mathrm{M}$ website views per year

At BMC, research is always in progress.

Learn more biomedcentral.com/submissions 